\title{
Quality of life in spina bifida: importance of parental hope
}

\author{
Haresh M Kirpalani, Patricia C Parkin, Andrew R Willan, Darcy L Fehlings,
} Peter L Rosenbaum, D King, Alison J Van Nie

\begin{abstract}
Background and aims-Prognosis in spina bifida (SB) is often based only on neurological deficits present at birth. We hypothesised that both parental hope and the neurophysical examination predict quality of life in children and adolescents with SB. Methods-A previously validated disease and age specific health related quality of life (HRQL) instrument was posted to families of children (aged 5-12 years) and adolescents (aged 13-20 years) with SB. We measured parental hope, determined the child's current physical function, and obtained retrospective data on the neonatal neurophysical examination (NPE). Regression analysis modelled HRQL firstly as a dependent variable on parental hope and NPE ("birth status"); and secondly on parental hope and current physical function ("current function"). Results-Response rates were $71 \%$ (137 of 194) for families of children, and $54 \%$ ( 74 of 138) for families of adolescents. NPE data were available for 121 children and 60 adolescents. In children, the birth status model predicted $26 \%$ of the variability $\left(\mathbf{R}^{2}\right.$ hope $21 \%$ ) compared with $23 \%$ of the variability $\left(R^{2}\right.$ hope $\left.23 \%\right)$ in the adolescents. The current function model explained $47 \%$ of the variability $\left(R^{2}\right.$ hope $\left.19 \%\right)$ in children compared with $31 \%$ of the variability ( $R^{2}$ hope $24 \%$ ) in the adolescents. Conclusions-In both age groups, parental hope was more strongly associated with the HRQL than neonatal or current physical deficits. A prospective study is required to determine whether a causal relation exists between parental hope and HRQL of children and adolescents with SB. (Arch Dis Child 2000;83:293-297)
\end{abstract}

Keywords: spina bifida; health related quality of life; hope; newborn

Spina bifida (SB) is a serious congenital anomaly with an incidence of $0.4-1.0$ per 1000 births in the USA. ${ }^{1}$ Universal folic acid supplementation will reduce, but not entirely eliminate neural tube defects. ${ }^{2}$ The sequelae of SB include decreased mobility, bladder and bowel incontinence, ${ }^{1}$ and neurosensory disabilities as well as social disadvantages such as decreased community acceptance and lack of a supportive peer network. ${ }^{3-5}$ In addition, SB has major financial and employment implications for affected families. ${ }^{4}$

Improved operative interventions for SB (and particularly for hydrocephalus) during the neo- natal period became available after 1960 and highlighted the need for the development of treatment guidelines. The therapeutic pendulum has swung considerably; from recommendations for active therapy regardless of the level of lesion ${ }^{6-8}$; to a selective treatment based on deficits assessed by a neurophysical examination $(\mathrm{NPE})^{7-11}$; and back to aggressive therapy for virtually all patients. ${ }^{1}$ This latter approach follows concerns about the predictive accuracy of the NPE, the ethics of selective practices, ${ }^{12-15}$ and the survival of non-operated infants. ${ }^{13-15}$

Given the uncertainty about the best management for an individual infant with $\mathrm{SB}$, it has been suggested that "parental directives for care" might resolve some of the dilemmas that arise when health caregivers make judgements about their patients' future quality of life. ${ }^{16}$ This suggestion is in keeping with an increasingly heard request for more parental involvement in medical decisions for critically ill newborns. ${ }^{17}$ Nonetheless, in order to make rational decisions, parents need accurate prognostic information; the NPE is used commonly to predict future physical and cognitive function. ${ }^{18}$ Moreover, in clinical practice, limitations in mobility, bladder and bowel function, and cognitive development are often used to predict an individual's future health related quality of life (HRQL), despite the absence of empirical data on the predictors of HRQL in this population.

In our work with parents of children with spina bifida, it was suggested that factors other than NPE might predict children's HRQL. One hypothesised factor was level of parental hopefulness. Advisors from the Spina Bifida and Hydrocephalus Association of Ontario agreed with the importance of a construct such as hope in modifying outcomes. The construct of hope has been described in the nursing, psychological, and sociological literature. ${ }^{19-31}$ It has been suggested that hope is essential for mental health, ${ }^{19-21}$ for coping and adapting, ${ }^{22}$ and for sustaining and energising a mother's maternal work in the care of her disabled child. ${ }^{23}$ Hope is increasingly recognised as a disease modifier. ${ }^{24-26}$ We therefore hypothesised that parental hope is an important determinant of HRQL in SB.

The objectives of our study were to evaluate the relative contributions of neonatal and current physical function, and of parental hope, to the HRQL of children and adolescents with SB.

\section{Methods}

STUDY POPULATION

Following initial surgery, all children with SB in Ontario are referred to a regional, publicly funded specialist treatment centre for ongoing care. We obtained patient lists from two such regional centres. Chedoke-McMaster Hospitals 
serves the Hamilton-Wentworth region of Ontario and follows approximately 90 SB patients; the Bloorview MacMillan Centre serves the South Central region of Ontario and follows approximately $650 \mathrm{SB}$ patients. The study received ethical approval from these two institutions and from the Hospital for Sick Children in Toronto. A random sample was taken of all patients in the age groups 5-12 years and 13-20 years; their families received a postal enquiry as described below. This random selection ensured a representative sample of patients whose characteristics would cover the full range of disability and functional impairment.

PROCEDURE

Parents were asked for permission to retrieve their child's neurophysical examination findings from hospital records. In addition, parents were asked to complete a demographic data collection form, a form to describe current function, and the Miller Hope Scale. Parents of children aged 5-12 years were requested to complete the HRQL questionnaire on behalf of their child; adolescents aged 13-20 years completed this questionnaire themselves. Parental completion of the Hope Scale, and child completion of the HRQL occurred concurrently. To maximise response rates, we completed three mailings accompanied by two telephone calls which were spread over three months after the initial telephone call.

Demographic data and current functional status Demographic data included family income, place of residence (urban or rural), and family composition. In addition, data were obtained on the current level of physical function, including mobility, and degree of bladder and bowel independence. Finally, the number of previous medical interventions was recorded, including all shunt revisions, and the number of surgical operations the child had received.

Parental hope: the Miller Hope Scale (MHS)

This 40 item scale was devised by Miller and Powers $^{20}$ and validated in 522 adults. This instrument has good measurement properties including test-retest reliability. In a pilot group of parents of both 5-12 year old children and 13-20 year olds with spina bifida, we found that the MHS was easily administered. In both age groups, the MHS was completed by the same parent who provided the data on current function and demographics.

Quality of Life Scales (HRQL)

This self administered reliable and validated age specific instrument was devised following the general methodology outlined by Kirshner and Guyatt, ${ }^{32}$ and applied to HRQL. ${ }^{33}$ We have previously reported the methodological development of this instrument. ${ }^{34}$ The items for this instrument were generated through open ended interviews with families of children with SB. The items were then reduced, and validated by accepted techniques. ${ }^{33}$ Two age specific questionnaires were developed: for children aged 5-12 years (44 items), and for adolescents aged $13-20$ years ( 47 items). Items from several domains were included.
NEWBORN NEUROPHYSICAL EXAMINATION (NPE) Data on the NPE were retrieved from the newborn hospital record where available. Details of the NPE included head circumference and percentile at birth, and presence or absence of other congenital anomalies (that is, chromosomal anomalies and congential anomalies not typically associated with spina bifida). Level of the spinal cord lesion was judged from the hospital record by references to sensory function, muscle innervation level, muscle power, and the presence or absence of an anal wink. ${ }^{1}$ In a pilot study of 15 cases, there was $100 \%$ agreement of the information retrieved from the hospital record, as assessed independently by two individuals, a research assistant and a physician. For the entire study sample, two physicians independently rated the level of lesion for each study patient. (One physician is a neonatologist (HMK) and the other a tertiary care academic general paediatrician (PCP).) Inter-rater agreement was $85 \%$. A third physician, a developmental paediatrician (PLR), arbitrated the $15 \%$ of cases where HMK and PCP did not agree.

\section{STATISTICAL ANALYSIS}

Statistical analysis was performed using SAS (SAS Institute Inc., Cary, North Carolina). We performed two separate forward selection regression models in each age group. A linear least squares regression model was used. Terms with a significance level less than 0.05 were deemed to be statistically significant, and were added to the model.

The first analysis in each age group was termed the "birth status" model. This examined the extent to which the current HRQL of the child could be predicted from two sets of variables: the neurological status at birth using the NPE, and parental hope measured by the MHS.

The second regression model was termed the "current function" model. This analysis asked how much of the variability in the HRQL could be explained by the current physical function of the child, and by parental hope.

SAMPLE SIZE

We calculated post hoc that the respective sample sizes of 60 and 121 had provided us with $80 \%$ power at the $5 \%$ level for detecting an association between the MHS measure of parental hope and an independent variable if the strength of the correlations were 0.33 and 0.23 , respectively. ${ }^{35}$

\section{Results}

SUBJECT RESPONSES

The response rate was $71 \%$ (137 of 194 families) in the 5-12 year age group. The results of 121 matching NPEs (88\%) could be obtained. The remainder of the children were either born out of province or had inadequate details recorded. Current physical function was determined in all 137 children and 131 responses were received for the parental MHS.

In the 13-20 year age group, the response rate was $54 \%$ (74 of 138 families). The NPE was available in 60 of these. 
Table 1 Socioeconomic characteristics of the parents of children

\begin{tabular}{lll}
\hline & $\begin{array}{l}5-12 \text { years }(\%) \\
(n=121)\end{array}$ & $\begin{array}{l}13-20 \text { years }(\%) \\
(n=60)\end{array}$ \\
\hline $\begin{array}{ll}\text { Income levels } \\
\quad \$ 40000 / \text { year }\end{array}$ & 46 & 42 \\
$\quad \begin{array}{l}\text { \$20-40 000/year } \\
\quad 30-20000 / \text { year }\end{array}$ & 18 & 43 \\
Size of community & & 15 \\
$\quad$ Large urban & 50 & 38 \\
$\quad$ Rural or small urban & 50 & 62 \\
Family structure & & \\
$\quad$ Single parent families & 17 & 18 \\
$\quad$ Two parent families & 83 & 83 \\
Extended family support & & \\
$\quad$ Yes & 73 & 55 \\
$\quad$ No & 27 & 45 \\
\hline
\end{tabular}

Table 2 Functional characteristics of children sampled

\begin{tabular}{|c|c|c|}
\hline & $\begin{array}{l}5-12 \text { years } \\
(\%)\end{array}$ & $\begin{array}{l}13-20 \text { years } \\
(\%)\end{array}$ \\
\hline \multicolumn{3}{|l|}{ Bladder } \\
\hline Independent without catheter & 10 & 8 \\
\hline Independent with catheter & 44 & 66 \\
\hline Needs help & 47 & 26 \\
\hline \multicolumn{3}{|l|}{ Bowel } \\
\hline Independent (no enemas etc) & 32 & 32 \\
\hline Independent, needing enemas & 15 & 24 \\
\hline Needs help with bowels & 53 & 43 \\
\hline \multicolumn{3}{|l|}{ Mobility } \\
\hline Walks everywhere, no aids & 18 & 12 \\
\hline Walks with aids & 33 & 30 \\
\hline $\begin{array}{l}\text { Household walker and } \\
\text { wheelchair }\end{array}$ & 12 & 16 \\
\hline Full wheelchair & 37 & 42 \\
\hline \multicolumn{3}{|l|}{ Number of operations } \\
\hline 0 & 2 & 3 \\
\hline $1-3$ & 29 & 13 \\
\hline $4-5$ & 23 & 24 \\
\hline $6-10$ & 38 & 30 \\
\hline $11-20$ & 9 & 24 \\
\hline $21-30$ & 0 & 6 \\
\hline Maximum number of operations & 20 & 30 \\
\hline \multicolumn{3}{|l|}{ Number of shunt revisions } \\
\hline No shunt & 50 & 33 \\
\hline $1-4$ revisions & 40 & 51 \\
\hline$>4$ revisions & 10 & 16 \\
\hline
\end{tabular}

Table 3 Birth status model

\begin{tabular}{lllrrr}
\hline Age group & Steps & Variables & Coefficient & $R^{2}$ & p value \\
\hline 5-12 years & 1 & Parental MHS & 0.4793 & 0.207 & $<0.0001$ \\
& 2 & Level of lesion & 0.0227 & 0.051 & 0.0055 \\
& 3 & Head circumference & -0.0230 & 0.005 & 0.3634 \\
13-20 years & 4 & Congenital anomalies & 0.0080 & 0.001 & 0.7287 \\
& 1 & Parental MHS & 0.5570 & 0.234 & $<0.0001$ \\
& 2 & Level of lesion & 0.0170 & 0.017 & 0.2565 \\
& 3 & Head circumference & -0.0091 & 0.029 & 0.8092 \\
& 4 & Congenital anomalies & -0.0176 & 0.031 & 0.5990 \\
\hline
\end{tabular}

Table 4 Current function model

\begin{tabular}{|c|c|c|c|c|c|}
\hline Age group & Steps & Variables & Coefficient & $R^{2}$ & p value \\
\hline \multirow{7}{*}{$5-12$ years } & 1 & Parental MHS & 0.4173 & 0.188 & $<0.0001$ \\
\hline & 2 & Age & -0.0120 & 0.050 & 0.0007 \\
\hline & 3 & Number of operations & -0.0055 & 0.131 & 0.0014 \\
\hline & 4 & Bladder & -0.0688 & 0.102 & 0.0001 \\
\hline & 5 & Mobility & -0.0090 & 0.006 & 0.2522 \\
\hline & 6 & Bowel function & -0.0074 & 0.003 & 0.4316 \\
\hline & 7 & Number of shunt revisions & -0.0002 & 0.010 & 0.8267 \\
\hline \multirow[t]{7}{*}{$13-20$ years } & 1 & Parental MHS & 0.5171 & 0.238 & 0.0003 \\
\hline & 2 & Bowel function & 0.0406 & 0.072 & 0.0171 \\
\hline & 3 & Age & -0.0052 & 0.004 & 0.5447 \\
\hline & 4 & Number of operations & -0.0003 & 0.008 & 0.8484 \\
\hline & 5 & Mobility & -0.0123 & 0.010 & 0.3269 \\
\hline & 6 & Bladder & -0.0569 & 0.041 & 0.0402 \\
\hline & 7 & Number of shunt revisions & 0.0008 & 0.008 & 0.4049 \\
\hline
\end{tabular}

CHILD AND FAMILY CHARACTERISTICS

Table 1 outlines the socioeconomic characteristics of the families in the two age groups. Table 2 presents details of the children's characteristics including the child's physical function as assessed by the families and by teenagers themselves, for bowel and bladder function, degree of mobility, and the number of operative procedures and shunt procedures.

REGRESSION ANALYSIS

The full details of the final regression models are presented by age group, in Appendix 1. Further detailed results are presented in the tables. Table 3 summarises the results for the birth status model for each age group. Table 4 summarises the results for the current function model.

Birth status model

This model explained $26 \%$ (total $\mathrm{R}^{2}$ ) of the variance of HRQL in children aged 5-12 years and $23 \%$ in adolescents aged 13-20 years. In both age groups, the explanation provided by the parental MHS was far greater than that provided by any other variable.

\section{Current function model}

In the younger age group, this model explained $47 \%$ of the variance associated with HRQL. The variance was mainly explained by MHS, bladder function, and the number of surgical operations. In the older age group, this model explained $31 \%$ of the variance associated with HRQL, with MHS and bowel function contributing most importantly.

\section{Discussion}

In this study, we found a striking association between the child's HRQL and parental hope. In contrast, physical limitations which clinicians commonly use to predict HRQL appeared to be less important. Our data are consistent with the view that some of the ethical concerns surrounding the prediction of outcome for newborn infants with SB can only be solved by a better understanding of family desires, problems, and coping strategies. ${ }^{16}$

Previous work has shown that perceptions of HRQL in SB and other disabilities vary considerably between different observers. Cadman et al reported that parents of children with and without disabilities perceive physical and mental handicaps very differently from health care professionals. ${ }^{36}$ Other investigators have shown that in contrast to physicians who care for children with SB, parents do not view those children as being sick. ${ }^{57}$ In the present study, we have shown for the first time that differences in HRQL for children and adolescents can be attributed, at least in part, to differences in the degree of parental hope. Taken together, these findings suggest that health professionals should exercise extreme caution when attempting to predict an individual child's HRQL based on physical symptoms and signs. As patients and their families are the best judges of their own HRQL, we do not support the recent approach by Takayanagi and Suruga ${ }^{38}$ to determine quality of life in neonatal surgical cases, 
as it is based on the assessment of medical providers rather than of parents.

Hope is a construct that has been extensively explored in the nursing, psychological, and sociological literature, and reliable and valid scales for its measurement have been devised, including the one used in this study. ${ }^{20}$ The Miller Hope Scale has been found to be correlated with religiosity, spiritual well being, hope, and other positive mood states ${ }^{21}$; the coping effectiveness $^{22}$; social support and self esteem $^{27}{ }^{29}$; resolution of psychosocial issues and the perception that one is able to control one's life $\mathrm{e}^{28}$; and psychological well being. ${ }^{19} 20$ Larson $^{23}$ has found that hopefulness is critical for sustaining and energising a mother's maternal work in the care of her disabled child. Hope is increasingly recognised as a disease modifier, ${ }^{24-26}$ although we are only beginning to understand how hope (and hopelessness) affect biological processes.

This study has limitations. We used proxy responses from parents to judge HRQL for children aged 5-12 years, while adolescents rated their own HRQL. Importantly, whether or not a parental proxy was used to determine HRQL, a strong association was found between parental hope and HRQL. Another limitation to the interpretation of the relation between parental hope and HRQL results from the cross sectional nature of the study. It is possible that parental hope is a reflection of the experiences of the family, or that parental hope directly influences the child's HRQL. The latter interpretation seems plausible, given that the construct of hope has been linked with positive psychological factors as noted above. Parents caring for a child with a physical disability may well empower their children with a similar sense of hopefulness, which may result in an improved perception of their HRQL.

It is not known whether hope is a static trait or a dynamic state. If hope is a trait, that is, a stable personality or temperamental characteristic, it follows that hope is likely to be a true determinant of HRQL. If hope is a dynamic state, it may potentially be responsive to targeted interventions. It has already been shown that a prospective nursing intervention reduced maladjustment in children with chronic disorders. ${ }^{39}$ It is conceivable that nursing provision had in some way fostered hope. Wake and Miller have described several hope inspiring nursing strategies for treating hopelessness. ${ }^{3031}$ Furthermore, it is not known what the determinants of hope might be. It is possible that factors such as family income, family structure, or parents' level of education may in some way determine degree of parental hopefulness. Although several of these factors were measured in our study, we feel that determinants and dynamics of hope need new and prospective testing in future studies.

We would argue that more attention to the understanding and nurturing of hope is warranted in the long term care of children with SB and probably also in other childhood disorders. The importance of hope has been recognised by nurses and psychologists. It should be equally recognised by physicians caring for children.

The authors wish to thank Ms Bonnie Charbonneau of the Spina Bifida and Hydrocephalus Association (Canada), and Dr David Cadman for their insights; and Drs G Guyatt, D Streiner, and B Schmidt (McMaster University) for advice on the manuscript. This work was supported by grant number 02943 from the Ministry of Health Ontario and from Bloorview Children's Hospital Foundation.

\section{Appendix 1}

The final models are as follows.

BIRTH STATUS

5-12 year age group: $\mathrm{HRQL}=0.32+0.48$ (parental MHS) +0.02 (level of lesion)

13-20 year age group: $\mathrm{HRQL}=0.41+0.56$ (parental MHS)

\section{CURRENT FUNCTION}

5-12 year age group: $\mathrm{HRQL}=0.74+0.42$ (parental MHS) - 0.01 (number of operations) -0.07 (bladder function) -0.01 (age)

13-20 year age group: $\mathrm{HRQL}=0.53+0.52$ (parental MHS) - 0.04 (bowel function)

1 Noetzel MJ. Myelomeningocele: current concepts of management. Clin Perinatol 1989;16:311-29.

2 MRC Vitamin Study Research Group. Prevention of neural tube defects: results of the Medical Research Council vitamin study. Lancet 1991;338:131-7.

3 Richards ID, McIntosh HT. Spina bifida survivors and their parents: a study of problems and services. Dev Med Child Neurol 1973;15:292-304.

4 Castree BJ, Walker JH. The young adult with spina bifida. BMf 1981;283:1040-2.

5 Rasmussen F, Lie HR, Hagelsteen JH, Lagergren J, Borjeson MC, Lagerkvist B, Kohler L. Nordic children with myelomeningocele. Parents' assessment of the handicap and physicians' classifications of the disabilities. Acta Paediatr 1993;82:276-80.

6 Laurence KM. Effect of early surgery for spina bifida cystica on survival and quality of life. Lancet 1974;i:301.

7 Lorber J. Results of treatment of myelomeningocele. An analysis of 524 unselected cases, with special reference to possible selection for treatment. Dev Med Child Neurol 1971;13:279-303

8 Lorber J. Spina bifida cystica. Results of treatment of 270 consecutive cases with criteria for

9 Hunt G, Lewin W, Gleave J, Gairdner D. Predictive factors in open myelomeningocele with special reference to in open myelomeningocele with

10 Evans RC, Tew B, Thomas MD, Ford J. Selective surgical management of neural tube malformations. Arch Dis Child 1985;60:415-19.

11 Stark GD, Drummond M. Results of selective early operation in myelomeningocele. Arch Dis Child 1973;48:676-83.

12 Duff RS, Campbell AG. Moral and ethical dilemmas in the special-care nursery. $N$ Engl F Med 1973;289:890-4

13 McLaughlin JF, Shurtleff DB, Lamers JY, Stuntz JT, Hayden PW, Kropp RJ. Influence of prognosis on decisions regarding the care of newborns with myelodysplasia. $N$ Engl f Med 1985;312:1589-94.

14 Charney EB, Weller SC, Sutton LN, Bruce DA, Schut LB. Management of the newborn with myelomeningocele: time for a decision making process. Pediatrics 1985;75:58-64.

15 Menzies RG, Parkin JM, Hey EN. Prognosis for babies with meningomyelocele and high lumbar paraplegia at birth. Lancet 1985;ii:993-5.

16 Gross RH. Newborns with myelodysplasia-the rest of the story [editorial]. N Engl f Med 1985;312:1632-4.

17 Harrison $\mathrm{H}$. The principles for family-centered neonatal care. Pediatrics 1993;92:643-50.

18 Mapstone TB, Rekate HL, Nolsen FE, Dixon MS Jr, Glaser N, Jaffe M. Relationship of CSF shunting and IQ in children with myelomeningocele: a retrospective analysis. Childs Brain 1984;11:112-18.

19 Taylor SE, Brown JD. Illusion and well-being: a social psychological perspective on mental health. Psychol Bull 1988;103:193-210.

20 Miller JF, Powers MJ. Development of an instrument to measure hope. Nurs Res 1988;37:6-10.

21 Fehring RJ, Miller JF, Shaw C. Spiritual well-being, religiosity, hope, depression, and other mood states in elderly people coping with cancer. Oncol Nurs Forum 1997;24:663-71.

22 Hirth AM, Steward MJ. Hope and social support as coping resources for adults waiting for cardiac transplantation. resources for adults waiting for
Can $\mathcal{F}$ Nurs Res $1994 ; 26: 31-48$.

23 Larson E. Reframing the meaning of disability to families: the embrace of paradox. Soc Sci Med 1998;47:865-75. 
24 Snyder CR, Irving LM, Anderson JR. Hope and health. In: Snyder CR, Donelson RF, editors. Handbook of social and clinical psychology: the health perspective. New York: Pergamon Press, 1991:285-305.

25 Kirkpatrick H, Landeen J, Byrne C, Woodside H, Pawlick J, Bernardo A. Hope and schizophrenia. Clinicians identify hope-instilling strategies. F Psychosoc Nurs Ment Health Serv 1995;33:15-19.

26 Molassiotis A, Van Den Akker OB, Milligan DW, Goldman JM. Symptom distress, coping style and biological variables as predictors of survival after bone marrow transplantation. 7 Psychosom Res 1997;42:275-85.

27 Piazza D, Holcombe J, Foote A, Paul P, Love S, Daffin P. Hope, social support and self-esteem of patients with spinal cord injuries. F Neurosci Nurs 1991;23:224-30.

28 Brackney BE, Westman AS. Relationships among hope, psychosocial development, and locus of control. Psychol Rep 1992;70:864-6.

29 Foote AW, Piazza D, Holcombe J, Paul P, Daffin P. Hope, self-esteem and social support in persons with multiple self-esteem and social support in perso
sclerosis. 7 Neurosci Nurs 1990;22:155-9.

30 Miller JF. Hope-inspiring strategies of the critically ill. Appl Nurs Res 1989;2:23-9.

31 Wake MM, Miller JF. Treating hopelessness: nursing strategies from six countries. Clin Nurs Res 1992;1:347-65.
32 Kirshner B, Guyatt G. A methodological framework for assessing health indices. F Chron Dis 1985;38:27-36.

33 Guyatt GH, Feeny DH, Patrick DL. Measuring health related quality of life. Ann Intern Med 1993;118:622-9.

34 Parkin PC, Kirpalani HM, Rosenbaum PL, Fehlings DL, Van Nie A, Willan AR, King D. Development of a health-related quality of life instrument for use in children with spina bifida. Qual Life Res 1997;6:123-32.

35 Snedcor GW, Cochran WG. Statistical methods, 6th edition. Ames, Iowa: The Iowa State University Press, 1967.

36 Cadman D, Goldsmith C, Bashim P. Values, preferences, and decisions in the care of children with developmental disabilities. F Dev Behav Pediatr 1984;5:60-4

37 McCormick MC, Charney EB, Stemmler MM. Assessing the impact of a child with spina bifida on the family. Dev Med Child Neurol 1986;28:53-61.

38 Takayanagi K, Suruga K. New approach to assess quality of life in neonatal surgical cases: medical providers' subjective assessment of disease- and condition-related factors using the linear of disease- and condition-related factors using the linear analogue scale. F Pediatr Surg 1994;29:659-62. 9 Pless IB, Feeley N, Gottlieb L, Rowat K, Dougherty G, Willard B. A randomized trial of nursing intervention to promote the adjustment of children with chronic physical disorders. Pediatrics 1994;94:70-5.

\section{Why us? Why me?}

Guiding parents through the diagnosis and management of rare and devastating conditions is difficult and draining. Perhaps the most tricky question to tackle is "why us?". Most people are unable to assess probability and, even if they can understand how often in the population an event might occur, this rarely translates into an appreciation of the chances of such an event happening to them. ${ }^{1}$ The rarity of such an event makes it difficult to believe and make sense of why it has happened to any one individual.

Having been a consultant paediatrician for ten months, I have found counselling parents facing these diagnoses one of the hardest aspects of my job. I am, however, getting a surprising amount of practice. Recent discussions in the medical and lay press, combined with a somewhat warped sense of fascination with probability and increasing disbelief relating to my experiences this year, led me to wonder if I am getting a predictable amount of practice, or if is this a highly unlikely sequence of events.

I am part time, so carry about a tenth of the workload. Thus, I can calculate the probability that I might be the consultant responsible for any patient newly diagnosed with each condition in any one year in my district (table 1). If I am right, and each event is independent of the other, multiplying these probabilities together should give the probability of children with all of these conditions diagnosed in one year in Portsmouth being admitted under my care.

This makes the probability of a paediatrician with a tenth of the workload in Portsmouth seeing all these conditions in one year, $6.1 \times 10^{-16}$ or 1 in 1633 billion.

We like to rely so much on measurement to help us make sense of what is happening in medicine. In this case, as the numbers get smaller (or bigger), they seem increasingly ridiculous. The reality of my caseload reminds me that this is really happening but the figures suggest it almost certainly isn't. I haven't spent too long wondering "why me?". I have learned such a lot in this crash induction into consultant practice, perhaps most of all, the value of supportive colleagues. Of course for me the question "why?" doesn't intrude on my life and belief structure at all, but for parents it often remains the most difficult part to come to terms with. Knowing the chances of a rare event happening are no comfort once it has done so and the question being asked is "why?".

The author would like to thank those who checked her maths.

Consultant Paediatrician

LIZ DONOVAN

St Marys Hospital

Portsmouth PO3 $6 A D$

Elizabeth.Donovan@SMAIL01.porthosp.swest.nhs.uk

1 Calman KC. Risk language and dialects. BMF 1997;315:939-42.

2 Croaker GDH, Shi E, Simpson E, Cartmill T, Cass DT. Congenital central hypoventilation syndrome and Hirshprungs disease. Arch Dis Child 1999;78: 316-22.

3 Tolavara MM, Harris JA, Ordway DE, Vargerik K. Birth prevalence, mutation rate, sex ratio, parents age and ethnicity in Aperts Syndrome. Am $\mathcal{F}$ Med Genet 1997;72:394-8.

4 Pollitt RJ, Leonard JV. Prospective surveillance of MCAD deficiency in the UK. Arch Dis Child 1998;79:116-19.

5 JH Walter, JE Collins, JV Leonard, Recommendations for the management of galactosaemia on behalf of the UK Galactosaemia Steering Group. Arch Dis Child 1999;80:93-6.

6 Burd L, Vesely B, Martsolf J, Kerbeshian J. Prevalence study of Prader Willi syndrome in North Dakota. Am F Med Genet 1990;37:97-9.

7 Heim P, Claussen M, Hoffmann B. Leukodystropy incidence in Germany. Am $\mathcal{F}$ Med Genet 1997;71:475-8

8 McClure RJ, Davis PM, Meadow SR, Sibert JR. Epidemiology of Munchausen syndrome by proxy, non accidental poisoning and non accidental suffocation. Arch Dis Child 1996;71:57-61.

\section{Editor's note}

As a new consultant nearly 25 years ago, I came across a similar improbability list for GPs, written by the late Professor R S Illingworth. I used it in teaching for a decade or so, then lost the reference. Does anyone have it?

Table 1 Incidence and probability of disease occuring in Portsmouth

\begin{tabular}{|c|c|c|c|}
\hline Condition & Incidence/ birth prevalence & In Portsmouth (6000 deliveries/year) & $\begin{array}{l}\text { Probability of seeing in any one } \\
\text { year on } 1 \text { in } 10 \text { rota }\end{array}$ \\
\hline Ondine's/Hirschsprung's /Neuroblastoma ${ }^{2}$ & 1in 1.4 million & 1 in 233 years & 0.00043 \\
\hline Apert's (normal twin) ${ }^{3}$ & 1 in 80000 & 1 in 13 years & 0.00769 \\
\hline $\mathrm{MCAD}^{4 \star}$ & 1 in 22000 & 1 in 3.6 years & 0.02732 \\
\hline Galactosaemia $^{5}$ & 1 in 450000 & 1 in 7.5 years & 0.01333 \\
\hline Prader-Willi ${ }^{6}$ & 1 in 16000 & 1 in 2.6 years & 0.03846 \\
\hline Pelizaeus-Merzbacher's (conatal form) ${ }^{7}$ & 1 in 770000 & 1 in 128 years & 0.00078 \\
\hline Munchausen syndrome by proxy $(<1 \text { year old })^{8}$ & 1 in 35700 & 1 in 5.9 years & 0.01695 \\
\hline
\end{tabular}

MCAD, medium chain acyl-CoA dehydrogenase deficiency. 